\title{
Large-scale regionalised LCA shows that plant-based fat spreads have a lower climate, land occupation and water scarcity impact than dairy butter
}

\author{
Xun Liao $^{1,2}$ (1) $\cdot$ Monique J. W. Gerichhausen $^{3} \cdot$ Xavier Bengoa $^{1} \cdot$ Giles Rigarlsford $^{4} \cdot$ Ralph H. Beverloo $^{5}$. \\ Yvonne Bruggeman $^{3}$. Vincent Rossi ${ }^{1}$
}

Received: 13 July 2018 / Accepted: 5 September 2019 /Published online: 13 January 2020

(C) The Author(s) 2020

\begin{abstract}
Purpose In light of the sustainable diet debate, we conducted a large-scale regionalised LCA to answer the following questions: (i) does the climate advantage hypothesis of plant-based fat spreads and creams over dairy butter and cream hold regardless of the variabilities of product recipes, geographies and the influence of land use change (LUC)? (ii) Considering the climate-water-land nexus, is there a risk of shifting impacts from climate to water scarcity and land occupation, and what are the key opportunities for impact mitigation?

Methods A framework for conducting a large-scale regionalised LCA was developed and applied to compare the environmental impacts of 212 plant-based fat spreads, 16 plant-based creams and 40 dairy alternatives sold in 21 countries per $1 \mathrm{~kg}$ of product. Data was compiled for different product recipes, key ingredient sourcing countries, production factory locations, energy mixes, packaging designs, transportation and end-of-life scenarios. Spatially (archetype) differentiated agricultural life cycle inventory data were generated, as well as LUC emissions for agricultural ingredients. A total of 18 environmental indicators were assessed. Results and discussion All plant-based spreads had a significantly lower climate impact than butter, with and without LUC inclusion. The regionalised analysis highlighted large variabilities across products, ranging from 0.98 to 6.93 (mean 3.3$) \mathrm{kg} \mathrm{CO}_{2}{ }^{-}$ eq for 212 plant-based spreads and 8.08 to 16.93 (mean 12.1) $\mathrm{kg} \mathrm{CO}_{2}$-eq for 21 dairy butter with 95th confidence interval. The main drivers of GHG emissions for plant-based products are oilseed farming and the associated LUC emissions, which can vary significantly depending on type of oilseeds, quantity and sourcing country; in the worst-case scenario, the climate advantage is no longer valid due to LUC. Thus, the inclusion of LUC is essential for a robust assessment and hotspot identification. Overall, the risk of shifting impact was small, as most of the plant-based spreads also had lower impacts for water scarcity footprints and land occupation; 8 of the 212 products were not lower, due to oilseed ingredients with high embodied impacts.

Conclusions This study confirmed that plant-based spreads had lower climate, water and land impacts than butter, despite variability of product recipes, geographies and influence of LUC. This research offers a framework for performing regionalised agricultural LCA for a large portfolio of products thereby enabling identification of inter-product variabilities and hotspots for the development of mitigation strategies. Key mitigation opportunities include reducing oilseed ingredients' embodied impacts by optimising product recipe design and adapting supply chain sourcing and agricultural practice.
\end{abstract}

Xun Liao and Monique JW Gerichhausen are both first authors.

Responsible editor: Niels Jungbluth

Electronic supplementary material The online version of this article (https://doi.org/10.1007/s11367-019-01703-w) contains supplementary material, which is available to authorized users.

Xun Liao

xun.liao@quantis-intl.com

Monique J. W. Gerichhausen

Nutritionist.Benelux@Upfield.com

Extended author information available on the last page of the article
Keywords Plant-based fat spreads $\cdot$ Butter $\cdot$ Regionalisation Spatial differentiation - Climate change $\cdot$ Land occupation . Water scarcity footprint

\section{Introduction}

Food production is estimated to be the largest cause of global environmental change, and the food sector is responsible for up to $30 \%$ of global greenhouse gas emissions (Vermeulen et al. 2012). Replacing production and consumption of animalbased food sources by plant-based alternatives could be a way to reduce the current impact of food production 
(Ranganathan et al. 2016; Poore et al. 2018; Willett et al. 2019). Previous studies show that the production of some plant-based spreads (seven products in UK, Germany and France) have lower climate change impacts and less land use compared with dairy butter (Nilsson et al. 2010; Milà i Canals et al. 2013); however, several critical gaps remain to fully understand the environmental performance between large variety of plant-based spreads and dairy butters sold in broad consumer markets. Firstly, a large spatial heterogeneity in environmental impacts may exist when producing the same agricultural products sourced from different producers and locations, with different agricultural practices (Poore et al. 2018) and embedded natural variabilities in different locations (Hellweg and Milà i Canals 2014); thus, there is a need to consider more geographies than the three country markets that were included in the earlier study. Furthermore, plant-based fat spreads sold in different countries have various product recipe design influenced by consumer preferences, packaging choices and supply chain logistics; however, these product-specific variabilities have not been comprehensively examined in terms of their influence on environmental impacts, from agricultural ingredient sourcing and production, through to processing, manufacturing, packaging, distribution, retailing, use and product end-of-life. Secondly, Poore et al. (2018) shows that the farm stage dominates GHG emissions from food, with most of them involving deforestation. Recent studies (Sandström et al. 2018; Pendrill et al. 2019) also find global agricultural commodity trade contributes to land use change (LUC) emission. The Nilsson study (Nilsson et al. 2010), comparing plant-based spreads and butter, only considered the GHG emissions from land use change (LUC) for a small selection of ingredients, such as palm oil; so the effect of comprehensively including LUC induced GHG emissions has yet to be considered. Thirdly, the available water remaining (AWARE) approach (Boulay et al. 2018) is recommended by the UNEP (UNEP 2016) and is also the default recommended method for assessing a water scarcity footprint by the Product Environmental Footprint Category Rules (PEFCR) Guidance (European Commission 2017). However, we did not find publications demonstrating an approach to operationalise regionalised LCA for a large portfolio of product recipes with complex agri-food supply chains for the same functionality, thus the feasibility of applying AWARE has yet to be tested. In light of the importance of the sustainable diet debate (Willett et al. 2019; Poore et al. 2018; Ranganathan et al. 2016), in this study, we aimed to propose an operational framework for performing a large-scale regionalised LCA to answer the following questions: (i) does the climate advantage hypothesis of plant-based fat spreads and creams over dairy butter and cream hold regardless of the variabilities of product recipes, geographies and the influence of inclusion of greenhouse gas ( $\mathrm{GHG}$ ) emissions from LUC)? (ii) Considering the climate-water-land nexus (Ringler et al. 2013; Kraucunas et al. 2015; Conway et al.
2015), is there a risk of shifting impacts from climate to water scarcity and land occupation, and what are the key opportunities for impact mitigation?

\section{Methods}

The LCA method aims to compare the environmental impacts of the production of dairy butter and creams with plant-based alternative products using a standard attributional approach as per the PAS 2050 (BSI 2012), aligning with the latest international standards for dairy products, published by the International Dairy Federation (IDF 2015) and the European Dairy Association (EDA 2016). This study is not intended for investigating a large-scale change of the two systems nor longterm consequences of a decision to switch from one system to another. For the butter (or Nordic dairy spreads) vs plant-based fat spreads comparison, the functional unit (FU) was $1 \mathrm{~kg}$ of product (fresh matter) for spreading, baking or shallow frying, at consumer level. For the dairy cream vs plant-based cream comparison, the FU was $1 \mathrm{~kg}$ product (fresh matter) for whipping or cooking, at consumer level. The choice of FU is discussed further in the sensitivity analysis section. To address the research questions above, we developed a regionalised LCA framework to consistently assess a large portfolio (228 plant-based spreads/ creams and 40 diary alternatives (see the supplementary material Section 3 for the definition of terminology)) of product recipes sold in 21 countries based on primary data from Upfield (previously Unilever's margarine business). The methodological framework is presented in Fig. 1, illustrating the main procedural steps, which is inherently iterative. It starts from goal and scope definition, which define the objectives, product systems, data quality requirement and cut-off criteria, as well as spatiotemporal context. In this study, the goal and scope define the overall data quality requirement using "minimal significance level" based on expert judgement for the difference of comparative study results to be considered as significant (see Electronic Supplementary Matrial-ESM_1.docx. Table S3 for minimal significance level definition). It further defines data quality requirement using pedigree scores See the supplementary material Table S6 for key processes (notably agricultural oilseeds LCI datasets) identified through the gap and prioritisation process, which further involved sensitivity analysis of choices related to allocation, models and assumptions together with parameter uncertainty analysis. Results obtained from each step are evaluated against the predefined data quality requirement. In terms of spatial scope definition, the regionalised LCA conducted was required at the country scale for key life cycle stages. It includes variations in product recipes, key agricultural ingredients' country of origin and corresponding country-specific agricultural practices and embedded natural variations (such as fertilisation, tillage practice, irrigation, yield, climate, soil properties), production factories and energy mixes, as well as packaging 


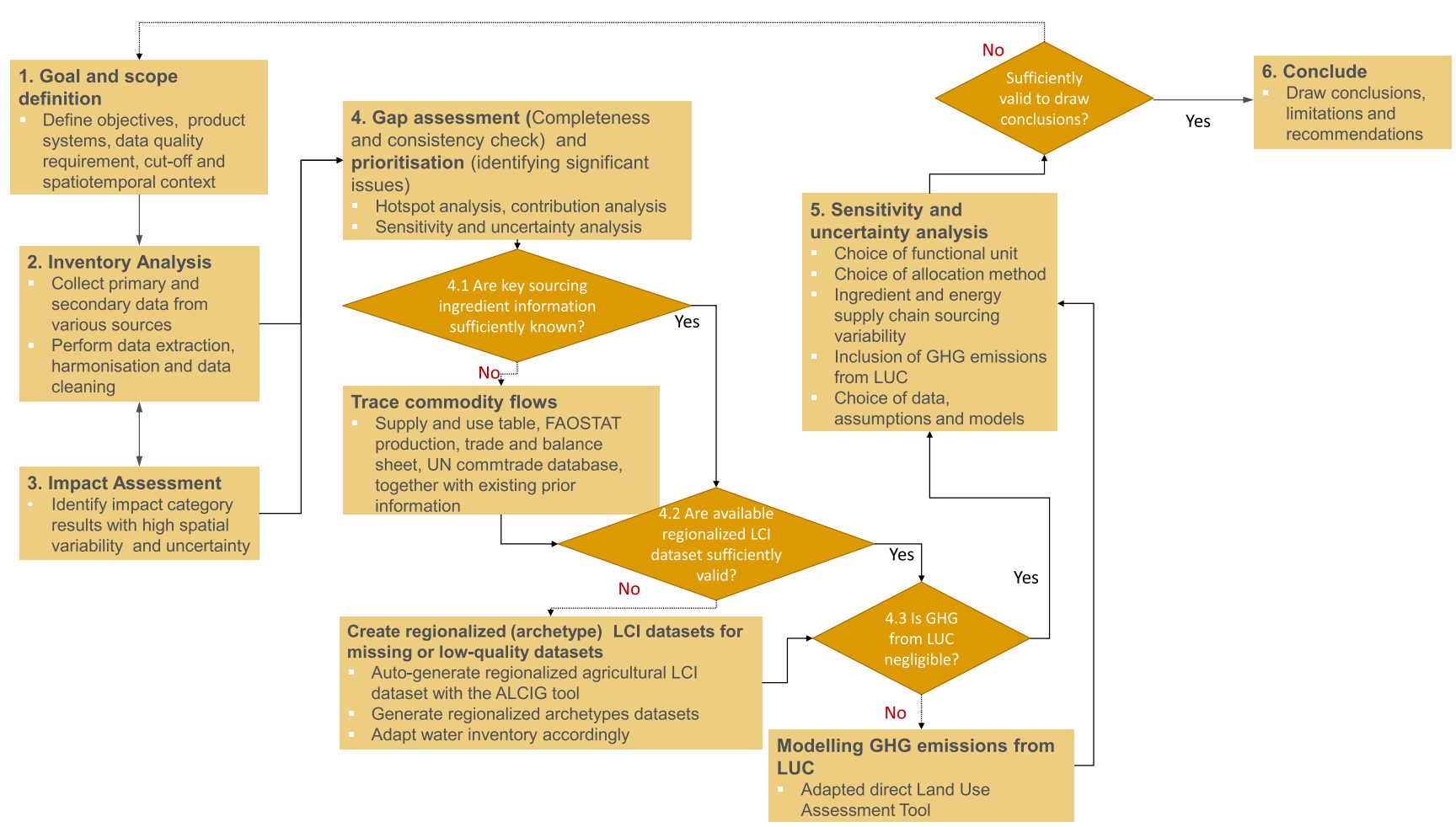

Fig. 1 Methodological framework developed in the study

designs, transportation distances and packaging materials' endof-life. More detailed descriptions of each step are provided in the ESM (ESM_1.docx. Section 1).

The following sections give further descriptions of product recipes, system boundaries, data collection, regionalisation of supply chain, spatial (archetype) LCI development, treatment of LUC and water flow modelling, allocation procedures, sensitivity analyses and parameter uncertainty assessment for climate change results.

\subsection{Products studied}

A total of 228 plant-based spreads/creams are assessed. Of them, 201 had no butter fat and 27 were blended with a small amount of butter fat (less than 18\%). For products used mainly for spreading and for baking or shallow frying, we assessed 212 predominately plant-based spreads with different levels of fat and types of packaging, sold in 21 markets in Europe and North America. The plant-based spreads were compared with local butter substitute. Additionally, for Nordic countries, (Denmark, Finland and Sweden) the plant-based spreads were also compared to spreads with $40 \%, 60 \%$ and $75 \%$ dairy fat (containing no vegetable fat). Plant-based spreads are packaged in various tubs or wrappers of different shapes and volumes (dairy spread packaging is the same as plant-based spread tubs in Denmark, Finland and Sweden), whereas typical packaging for butter in Europe is aluminium foil laminated paper, or waxed paper in North America. For creams, used for whipping or cooking, we assessed 16 plant-based cream recipes and compared them with their dairy cream alternatives. Packaging formats used for plant-based creams are identical to that of dairy creams (polyethylene terephthalate (PET) bottle or liquid packaging board, depending on the market). The numbers of plant-based spreads/ creams and their dairy substitute in each consumer markets are given in the ESM (ESM_1.docx. Table S1 and Table S2).

\subsection{System boundaries and cut-off}

The LCA considered all identifiable activities across the product life cycle (cradle-to-grave) for all products in the 21 markets where they are sold (see Fig. 2). Capital goods (ingredient delivery by trucks and ships, buildings, equipment, etc.) were included wherever data was available, such as for crop production, oil extraction and transformation and dairy processing. Capital goods at the distribution centre and the point of retail were not included as the contributions of these processes to the total system's environmental impacts were expected to be less than $1 \%$. The capital equipment and infrastructure processes from the ecoinvent database (v3.3) were used in the background system (Wernet et al. 2016). The following processes were left out of the system boundaries, consistent with attributional LCA practices: labour, commuting of workers, administrative work, cattle insemination and disease control. Food loss and food waste can take place at any stage in the products' life cycle. Statistical data at the national scale for specific product categories are not available and are therefore highly uncertain. At farm and processing level, losses are already accounted for in the processes' efficiency; therefore, 
Fig. 2 Schematic of the systems under evaluation

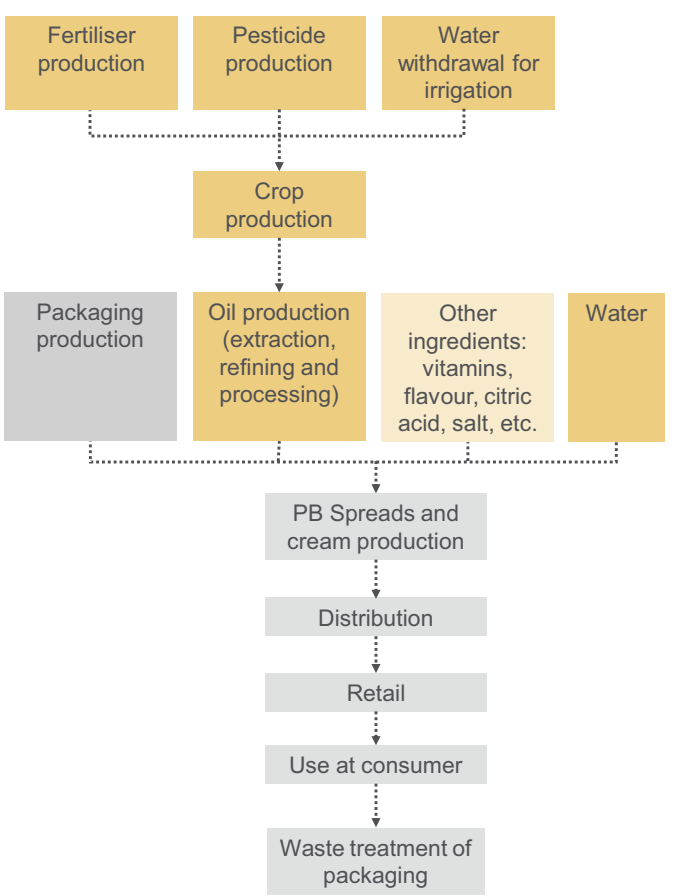

PB spreads and cream production

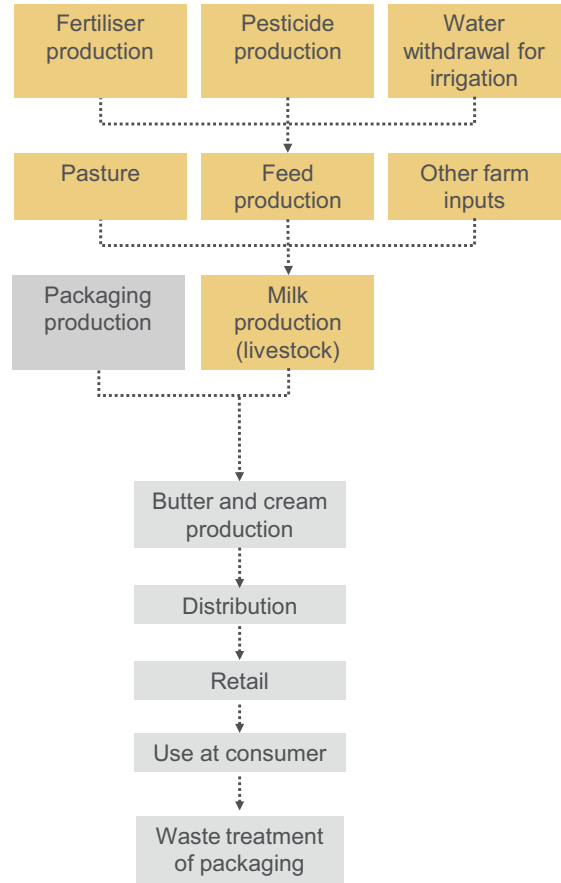

Butter and dairy cream production uncertainty remains regarding food losses and waste during distribution, at retail point and at the consumer's home. There is no evidence showing different food losses and waste rates between plant-based spreads and butter (and between plantbased creams and dairy cream). Further, the PEFCR for Dairy Products (EDA 2016) does not require the inclusion of food waste in the assessment but rather suggests a waste rate of $7 \%$ for butterfat products, tested in a sensitivity analysis. Food loss and waste during distribution, at retail point and at the consumer's home, is thus excluded from the scope of the study. Additional information is given in the ESM (ESM_1.docx. Table S4).

\subsection{Environmental impact indicators considered}

The assessment includes 15 environmental impact indicators from the European ILCD 2011 Midpoint+ v1.08 impact assessment method (JRC-IES 2011). Three additional indicators were included: land occupation $\left(\mathrm{m}^{2} /\right.$ year), which reflects the total area of land used over one year and is a proxy for biodiversity and ecosystem services (Nemecek et al. 2011; Milà i Canals et al. 2012), water consumption $\left(\mathrm{m}^{3}\right)$, the total amount of fresh water consumed (ISO 14046), which includes, for example, evapotranspiration from irrigation water, and water scarcity footprint $\left(\mathrm{m}^{3}\right.$ water equivalent (eq)) based on the AWARE approach that assesses the water deprivation potential considering spatial water scarcity differences (Boulay et al. 2018). Additional information is given in the ESM (ESM_1.docx. Table S3).

\subsection{Data sources, supply chain regionalisation and spatial (archetype) LCI modelling}

Primary data was collected from the manufacturer of the plant-based spreads and creams for all process stages within its control, namely recipe (i.e. ingredients and sourcing); oil processing where data is available e.g. from supplier or processing carried out by the manufacturer; product manufacturing; packaging materials weights and specifications; distribution transport distances from factories to markets. Secondary data was used to determine the bill of activities of other stages: crop production for oil crops and feed crops; raw milk production in each country; butter and cream production in each country; packaging materials and properties for butter and cream; distribution transport distances to point of sale (dairy products); storage at distribution centre and at point of sale; use stage; packaging end-of-life. Main data sources are summarised in the ESM (ESM 1.docx. Table S4). The detailed modelling steps are given below, following the described framework in Fig. 1.

\subsubsection{Tracing agricultural commodity country of origin}

Gap and prioritisation analysis of the preliminary LCA results indicates that the most important data to be improved are spatial differentiations of agricultural ingredients. The modelling of crop-country combinations for agricultural ingredients is described below: 
1. Identification of crop sources and vegetable oil refining activities. When primary data of sourcing of country of origins were unavailable or incomplete (e.g. countries or regions are known, but exact quantities are unknown), the sourcing mix was based on average historical (20062011) FAOSTAT data for import and domestic production (country of origin and \% sourcing). The model assumes that the final sourcing mix is proportional to the total of domestic and imported production volumes. A list of datasets accounting for parameters representative of average cultivation practices for each crop-country combination in the supply chain was developed for this study.

2. Gap assessment for spatially differentiated LCI data development. The availability and quality of spatially differentiated country-level LCI datasets were evaluated according to crop sourcing information and data quality requirements. A list of missing data for further development are identified.

3. Gap assessment for spatially differentiated elementary flows for impact assessment. Regionalised inventory data was further examined to evaluate the consistency with the requirements of the impact assessment methods. As a result, a customised version of ecoinvent v3.3 was developed to consistently support the AWARE method for the water scarcity footprint. The assessment of the water scarcity footprint indicator requires particular attention to the consistent modelling of all life cycle inventory data, both in the foreground and background systems. In the present study, all foreground and background inventory data were adapted to ensure the following: Water flows in every process were properly balanced, which enabled calculation of the amount of water consumed as the difference between inputs and outputs. Water flows were all regionalised at country level as per the location where the withdrawals (inputs) and releases (outputs) were taking place, therefore enabling the association to the appropriate characterization factor.

4. With key missing data identified, the sections below provide more details regarding generation of spatially differentiated (archetype) LCI datasets for plant-based and dairy products and the inclusion of GHG emissions from LUC.

\subsubsection{Spatially differentiated $\mathrm{LCl}$ data generation for plant-based products}

To conduct the gap assessment for plant-based spreads and plant-based creams, many of the regionalised LCI data were derived from the World Food LCA Database (WFLDB) v3.1 (Nemecek et al. 2015), which was updated with ecoinvent v3.3 data, system model "Allocation, cut-off by classification" (Weidema et al. 2013). The WFLDB was used as it provides unit process LCI data for many crops and countries, is representative of average production practices and includes data for dairy systems and processed food products.

For datasets with missing or low-quality data, additional LCI datasets were modelled using the Agricultural Life Cycle Inventory Generator (ALCIG) (Quantis 2016) consistent with the WFLDB approach for modelling the life cycle inventory of agricultural products (Nemecek et al. 2015). ALCIG calculates direct emissions at the farm, based on a number of customisable parameters such as input fertilisers and pesticides, soil type, climate conditions and farming practices (e.g. tillage). It integrates default values for most variables, based on statistical data from FAOSTAT, that can be used when specific data are not available. The ecoinvent database (v3.3) was used as a background database. Oil extraction and refining from agricultural oilseeds or crops are modelled based on data from Blonk Agri-footprint (2015) and Schau et al. (2016); separate LCI datasets were derived for crude oil extraction and refined oil production. Allocation of co-products is further discussed in Section 2.5.

\subsubsection{Spatial archetype LCI for dairy products}

The spatial archetype-based approach was introduced to account for the variability of key parameters influencing the environmental footprint of raw milk, such as herd size, breed, feed composition, intensity (i.e. degree of mechanisation) and manure management systems (MMS) in different countries. These parameters, except for the latter, influence the yield (i.e. $\mathrm{kg}$ raw milk per cow per year), the quality of the milk (i.e. fat and protein content) and direct emissions (through enteric fermentation and grazing) as well as the amount of manure to be managed. The dairy systems vary significantly between and within countries and therefore the approach applied by the WFLDB methodology guideline (Nemecek et al. 2015) was used to generate datasets representative of average raw milk production at a national scale. The country average dairy milk datasets are constructed in the following steps: firstly, 23 archetypes (or typologies) of milk production systems were modelled, based on the IFCN "typical farms" (FAO, IDF, IFCN 2014), and also specific studies for USA (Thoma et al. 2013) and Canada (DFC 2012). They describe how cows are fed and tended to at the farm, representing a selection of the diversity of dairy systems considered in the study. Production systems were characterised by their size (i.e. number of lactating cows) and different feeding patterns (i.e. grazing or nongrazing; proportions of hay, grains and compound feed in rations). To be consistent with prior modelling approaches, emission models for different manure management systems were created based on IPCC (2006) emission factors for methane $\left(\mathrm{CH}_{4}\right)$, nitrous oxide $\left(\mathrm{N}_{2} \mathrm{O}\right)$ and ammonia $\left(\mathrm{NH}_{3}\right)$. Six manure management systems are represented with up to three climate conditions (cool, temperate, warm). Each country 
has its own mix of manure management systems for dairy farming, as per FAO (2010a). Secondly, archetypes of typical dairy farms and MMS are combined in different proportions as to represent the typical dairy system mix in different countries. These mixes are mainly based on qualitative information retrieved from IDF and IFCN (FAO, IDF, IFCN 2014) and Eurostat 2013 data. All dairy farming modules generate milk as the main product, as well as live animals for slaughter or further fattening (i.e. male calves and culled cows) as co-products. The amount of milk produced is then corrected to a standard of $4 \%$ fat and $3.3 \%$ protein equivalent, according to the International Dairy Federation (IDF 2015) formula for fat and protein-corrected milk (FPCM). Additional detailed illustration and data are given in the ESM (ESM_1.docx. Section 2). Butter and cream processing data are based on EDA (2016), which provides typical data that can be used to represent average processing of dairy products. According to EDA (2016), the technology used in different countries is quite homogeneous, although higher variations are observable between large dairy farms and Small and medium farms. WFLDB datasets combine these data with complementary information from literature (Nemecek et al. 2015; Djekic et al. 2014, Flysjö 2012) to generate comprehensive LCI datasets. To regionalise the processing step, the national milk mix and national electricity consumption mix are used. Butter processing results in two other co-products: skimmed milk and buttermilk. Allocation among these co-products is discussed in Section 2.5.

\subsubsection{Modelling GHG emissions from land use change}

In crop production, global land transformation impacts are mainly driven by deforestation of primary forests. However, land use change (LUC) from deforestation of secondary forest or conversion from other types of land (grassland, perennial or annual crops) to arable land are also addressed. In agricultural systems, LUC can be an important contributor to GHG emissions (Poore et al. 2018). In this study, country-specific GHG emissions due to land use and LUC are assessed for each relevant vegetable oil ingredient and dairy feed input. The LUC impact assessment follows the framework defined in ecoinvent v3 (Nemecek et al. 2014), which is based on IPCC (2006) methodology. Land inventory data are obtained at the national level per crop and per type of land use based on FAO data (FAOSTAT 2012, FAO 2010b). Land use changes are calculated over the period 1990-2010. The LUC modelling approach builds on the Direct Land Use Change Assessment Tool Version 2013.1 (Blonk Consultants 2013) and is compliant with PAS 2050-1 protocol (BSI 2012). The amortization of GHG emissions is 20 years, which is aligned with PAS 2050-1 (BSI 2012) and FAO guidelines for feed supply chains (LEAP 2015). It accounts for all carbon pools i.e. above-ground biomass (AGB), below-ground biomass
(BGB), dead organic matter (DOM) and soil organic carbon (SOC) (Further data is provided in the ESM (ESM 1.docx. Table S5). The values for the relevant carbon pools were taken from the IPCC Agriculture, Forestry and Other Land Use report (IPCC 2006) and FAO (2010b), Annex 3, Table 11. Country climates and soil types were taken from the European Soil Data Centre (ESDAC 2010).

In this study, three major modifications were made to the original tool (Blonk Consultants 2013): (i) addition of the SOC-related emissions from peat drainage per hectare and year for pasture areas, using IPCC (2013) for emissions calculations, based on Joosten (2009) for the surface of forest grown on peatland in each country and emissions from peat degradation reported at the national scale for all countries in 2008; this adjustment is added because pasture is not included as a crop type and the degradation of drained peatland is not considered in the original Blonk tool; (ii) inclusion of carbon capture in vegetation when relevant (e.g. when grassland is transformed into perennial cropland); (iii) addition of $\mathrm{N}_{2} \mathrm{O}$ emissions related to SOC degradation according to IPCC (2006).

For climate change impacts from LUC, two allocation schemes corresponding to different "value systems" are considered: the "crop-specific" and "shared responsibility". The default allocation scheme used in this study is "crop-specific", while the "shared responsibility" approach is assessed in a sensitivity analysis.

- Crop specific: LUC is allocated to all crops and activities for which production area expanded over the last 20 years in a given country, according to their respective area increase.

- Shared responsibility approach: LUC during the last 20 years is evenly distributed among all crops and activities in the country, based on current area occupied.

\subsection{Allocation procedures}

A common methodological decision in LCA occurs when the system being studied produces co-products, such as vegetable oil and meal from oil extraction, or milk and meat from dairy farming. When systems are linked in this manner, the boundaries of the system of interest must be widened to include the system using all co-products, or the environmental impacts of producing the linked product must be attributed to the different co-products in the systems.

In this study, based on the Methodological Guidelines for Agricultural Products (Nemecek et al. 2015), economic allocation was used by default for crop co-products at the farm and also processed oil seeds ingredients. For dairy milk, upstream burdens and activities were allocated to the raw fat and protein-corrected milk (FPCM), using the IDF formula (IDF 
2015) and live animals based on biophysical criteria following the ISO hierarchy of allocation procedure (ISO 2006a, 2006b). For dairy butter and cream processing, the allocation of the upstream burden embodied in the raw milk as well as other inputs (energy, water, refrigerants) and outputs (wastewater, etc) is based on the dry weight (i.e. dry matter content) of butter and cream and its co-products, following the IDF (2015) and the European PEF category rules for Dairy products EDA (2016). All transport was assumed to be weightlimited due to the high density of the ingredients (oils and raw milk) and final products. For all packaging recycling processes, in alignment with ecoinvent methodology, the "cut-off by classification" approach was used to allocate recycled content and recycling at end-of-life (Ekvall and Tillman 1997). The allocation method used for background processes depends on the approach applied in the ecoinvent database. More details of allocation procedures and data are further elaborated in the ESM (ESM_1.docx. Section 4).

\subsection{Sensitivity and uncertainty analysis}

To ensure robustness of the LCA results, various sensitivity analyses were conducted in this project on the following key aspects: functional unit, LUC allocation approach, vegetable oils extraction allocation approach, worse case scenarios for supplying country of origins of main vegetable oils, packaging types and electricity production mix. To further improve robustness of climate change results, an uncertainty assessment has also been performed. Each product system is considered to include uncertainty with respect to (1) reference flows and (2) emission factors that are used to determine the LCI based on the reference flows. The parameter uncertainty is assessed with the Pedigree approach (Weidema et al. 2013). The total uncertainty of climate change results for butter and dairy cream is performed in SimaPro version 8.3 by running a Monte Carlo simulation of 1000 times. To assess the results' uncertainty of 228 plant-based spreads and plant-based creams, the analytical uncertainty propagation approach based on Taylor series expansion was used by adapting the uncertainty assessment method introduced by the GHG Protocol (2011). Results of sensitivity and uncertainty analysis are presented and discussed below in Section 3.

\section{Results and discussion}

For the LCA modelling tool, SimaPro version 8.3 was used to model individual datasets (such as oilseeds, packaging) required for plant-based products and also the whole life cycle of dairy products. Data from all life cycle stages of plant-based spreads were aggregated and assessed in a customised modular Excel model to enable efficient sensitivity and uncertainty analyses for the large portfolio of product scenarios in this study. The detailed results and discussions are given below.

\subsection{Overview of baseline results for plant-based spreads vs butter and dairy spreads}

Figure 3 illustrates the probability density function of six main impact indicators comparing 211 plant-based spreads with 21 butters sold in 21 consumer markets, using the non-parametric kernel density estimation (KDE) approach (One plant-based fat spread with very extreme value is excluded from the plotting). As shown in Fig. 3, large variabilities exist among product recipes. For 3 Nordic countries (Denmark, Finland, Sweden), dairy spreads are also studied. The comparison of plant-based spreads with dairy spreads and butter are shown in Fig. 4. Additional information is given in the ESM. (ESM_1.docx. Section 6 Figs S1-S5).

In statistics, kernel density estimation is a useful technique to visualise the shape based on finite data samples as in our study. The $x$-axis indicates the respective indicator results. The smaller the range of impact values of different products in $x$ axis, the higher the density value is. The integral of the shape for each type for a given impact indicator equals to 1 , the $100 \%$ of probability. The detailed discussions are given below for key environmental impact indicators of interests)

\subsubsection{Climate change impacts}

Figure 3 shows overall that plant-based spreads (mean $3.3 \mathrm{~kg}$ $\mathrm{CO} 2$-eq) in the 21 markets studied have lower climate change impacts than butter (mean $12.1 \mathrm{~kg} \mathrm{CO} 2$-eq); however, Fig. 5 shows the regionalised LCA results highlighted large variabilities on the individual product level, driven by difference in product recipe design and spatial variabilities of sourcing ingredients. Further details on uncertainty analysis (Section 3.5) and the influence of spatial LUC emissions (Section 3.3) are discussed below. Figure 4 shows for the 7 dairy spreads on the Nordic markets in Denmark, Finland and Sweden, climate change impacts are highly correlated with fat content. For dairy spreads with the lowest fat content $(40 \%$, in Finland and Sweden) climate change impacts are similar to those of plant-based spreads with the highest climate change impacts of all plant-based spreads (also see detailed aggregated country results in Fig. 9 below). However, when comparing plant-based spreads and dairy spreads sold in Finland and Sweden, climate change impacts are lower for the plantbased spreads.

Figure 5 shows, when considering impacts per life cycle stage, on average, the largest contributor for plant-based spreads is the production of the vegetable oil ingredients (2.24 $\mathrm{kg} \mathrm{CO} \mathrm{CO}_{2}$-eq $/ \mathrm{kg}$, $68 \%$ of total climate change impacts); whereas for dairy butter, the production of raw milk is the 

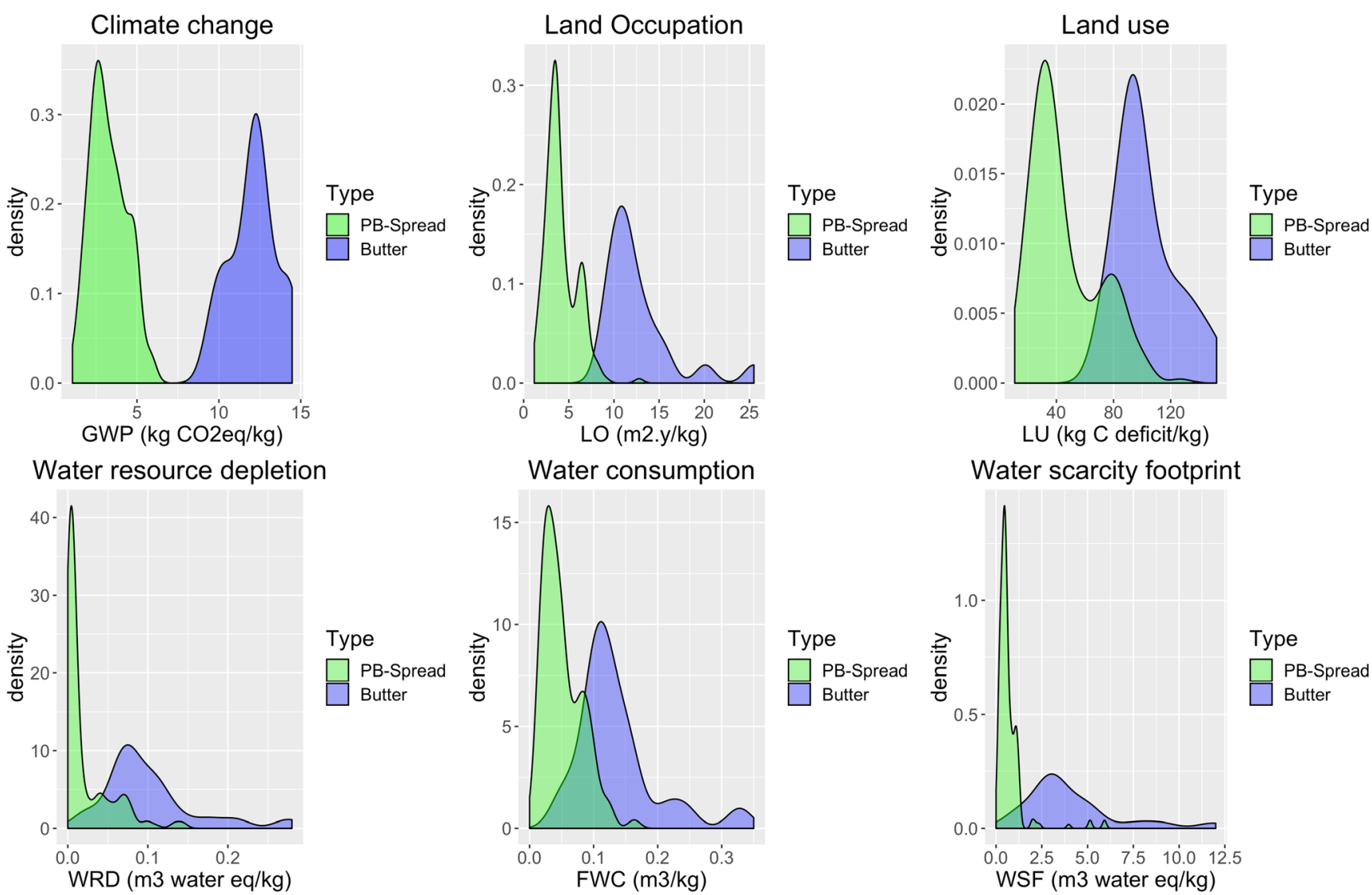

Fig. 3 Comparing environmental impacts of plant-based spreads with butter in all 21 countries (Fig. generated using "ggplot 2" package in R software (Wickham 2016)

main contributor for butter, contributing on average to $92 \%$ of total climate change impacts. Feed production and dairy farm activities such as methane emissions from enteric fermentation and manure management all contribute to climate change impacts. Packaging of plant-based spreads contributes $0.23 \mathrm{~kg}$ $\mathrm{CO} 2-\mathrm{eq} / \mathrm{kg}(7 \%)$; whereas for butter, packaging contributes on average $0.06 \mathrm{~kg} \mathrm{CO} 2-\mathrm{eq} / \mathrm{kg}$, which is less than $1 \%$ of total climate change impacts. This is due to differences in both the weight and type of packaging used with the butter being in lightweight paper either laminated in aluminium or waxed whereas the spreads are in heavier plastic tubs. Other notable difference includes production stage and distribution stage. Compared with plant-based fat spreads, dairy butter has higher production climate change impact, due to higher processing energy; on the other hand, it has lower climate impact related to the distribution phase, as it has much shorter distance required to distribute final product to final consumers with freezing transportation.

\subsubsection{Freshwater consumption, water scarcity footprint and water depletion potential}

For freshwater consumption and water scarcity results, Fig. 3 and Fig. 4 show there are high variabilities across product recipes and markets, driven by differences in yield and irrigation of crops and orchards. Figure 4 shows there are overlaps, particularly between plant-based spreads and dairy spreads with low fat (e.g. 40\%) levels, and also between butter and dairy spreads with high fat (e.g. 75\%) levels (See more details in ESM Fig. S3). This is because a higher fact content often leads to higher climate, water and land impacts, vice versa (See more details in the ESM, Fig. S1). In general, a linear relationship exists among solid content, fat content and calories (Nikolaou et al. 2016). A few exceptions of butters, notably in Ireland, have lower water consumption, due to embedded variabilities of dairy farming systems, influenced by different herd structures, feed intake compositions and manure management systems. The dairy farming systems in Ireland have a relatively higher proportion of pasture, hay, silage, haylage and agricultural residues rather than grains and concentrated feed (More details are available in the ESM, ESM 1.docx. Section 2 Spatial archetypes of dairy systems). For water scarcity footprint, most plant-based spreads (205 of 212 assessed) have a lower footprint in their respective consumer markets (see ESM, ESM_1.docx. Fig. S3), except for plant-based spreads containing dairy ingredients or oil seeds sourced from high water-stressed regions with low yields, such as olive oil from Tunisia. 

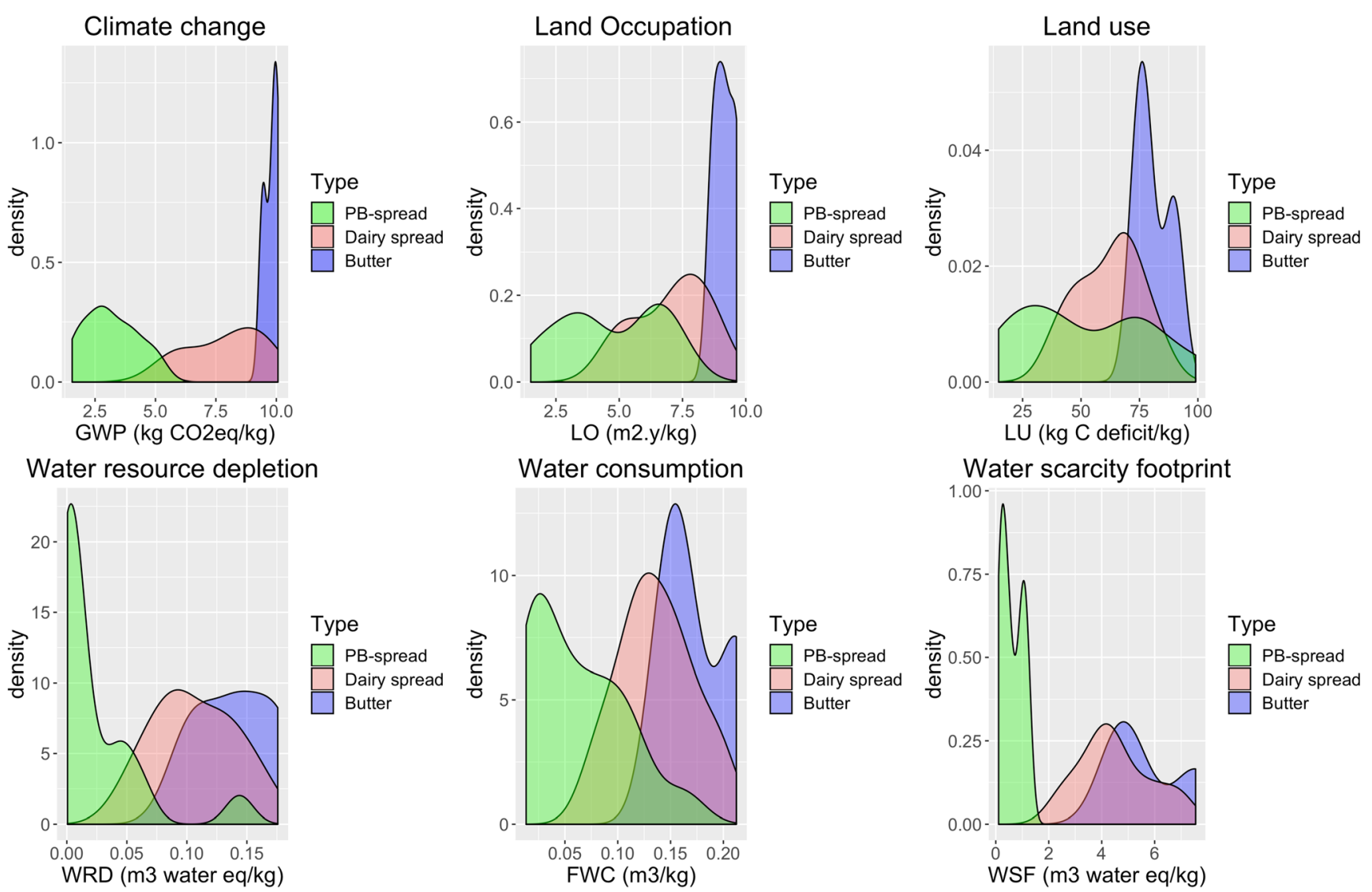

Fig. 4 Comparing environmental impacts of plant-based spreads with butter and dairy spreads in three Nordic markets (Denmark, Finland and Sweden)

\subsubsection{Land occupation and land use}

In terms of the surface areas required for land occupation, Fig. 3 and Fig. 4 show there are some overlaps between plant-based spreads and dairy butter if the constraints of consumer countries are ignored. However, it is found that most plant-based spreads (211 of the 212) have lower impacts compared with butter in their respective consumer markets, while some overlaps are observed when compared with dairy spreads. When considering the land use indicator, measured by soil organic carbon (SOC), there are more overlaps in results between plant-based spreads and both butter and dairy spreads in general or in their respective consumer markets (Also see more details about country-specific comparisons in the ESM, ESM_1.docx. Fig. S3).

Overall, when comparing plant-based spreads and dairy butter products, there is little risk of shifting climate impact to water and land related impact (See the ESM (ESM_1, Fig. S1)); however, special attention should be paid to agricultural ingredients from regions with high embodied land occupation or water scarcity footprint. There are opportunities for further reducing the environmental impact of plant-based fat spreads by e.g. adapting product recipes, opting for alternative agricultural oilseeds ingredients and/or adapting sourcing countries to avoid deforestation or other land use change-related climate risks. Meanwhile, it is also important to consider potential constraints, such as the choice of oils based on consumer preferences (taste, nutritional benefits and product function e.g. harder fats are used for products in warmer climates).

\subsubsection{Other indicators}

Plant-based spreads generally perform better than butter for a number of indicators including particulate matter, acidification and terrestrial eutrophication potentials, freshwater ecotoxicity, and mineral, fossil and resource categories. For the other impact indicators, significant overlaps exist between plant-based spreads and butter (available in the ESM, ESM_1.docx. Fig. S4).

\subsection{Overview of baseline results for plant-based creams vs dairy creams}

Figure 6 show the overall comparison of environmental impacts between plant-based creams and dairy creams in all 21 markets. For climate change, plant-based creams have lower climate change impacts compared with dairy creams, apart 


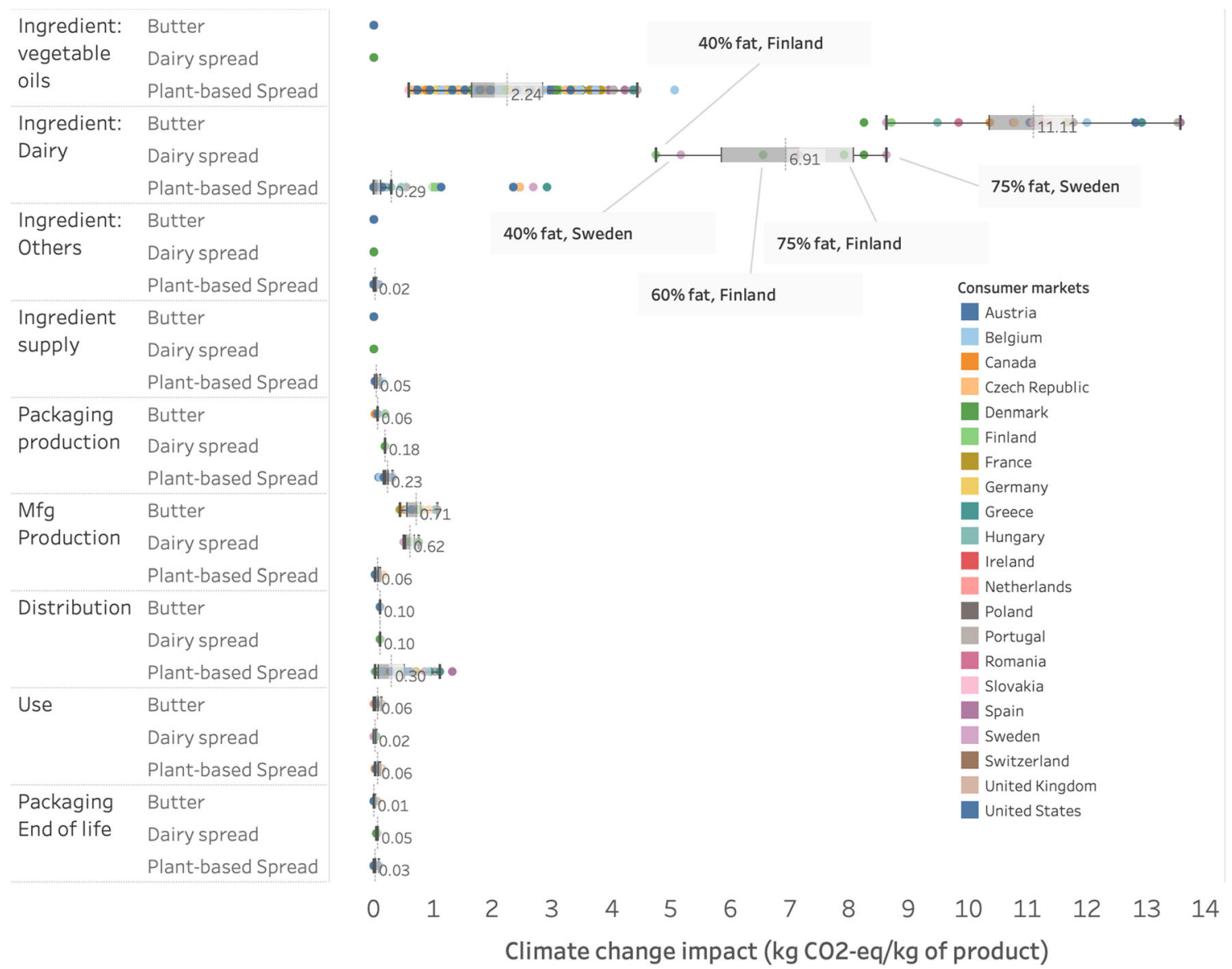

Fig. 5 Impact on climate change of 212 plant-based fat spreads, 7 dairy spreads and 21 butters per kilogram by life cycle stage (the average values are shown in the figure)

from those with very low-fat creams (15\% fat). For the other impact indicators, there are no significant differences between plant-based creams and dairy creams. More details are also given in the ESM (ESM_1.docx. Fig. S3 for details classified by consumer markets, $\mathbf{S} \overline{6}$ for the full 18 impact indicators, Fig. $\mathrm{S} 7$ for climate impact breakdown by life cycle stages).

\subsection{Understanding the influence of LUC on climate change}

LUC influences climate change impacts for plant-based spreads and plant-based creams, due to the production of key ingredients such as palm oil, coconut oil or soybean oil. Fig. 7 illustrates the contribution of LUC to climate change impacts of some ingredients included in the products. It shows that LUC alone can account for over $50 \%$ of climate change impacts of many ingredients, with the most extreme case being soybean oil from Brazil with a contribution of $86 \%$. Furthermore, the contribution of LUC also varies significantly among different ingredientcountry combinations. Understanding spatial sourcing of ingredients is important. On average, for the dairy butter products assessed, they have a higher LUC impact on climate change than plant-based fat spread products.

\subsubsection{The influence of allocation method choice for LUC}

With LUC considered in the model for all crop production activities, the share of LUC highly depends on the allocation approach. Therefore, a sensitivity analysis was performed to evaluate the influence on total climate change impacts for different scenarios by choosing the "shared responsibility" rather than the "crop-specific" allocation approach. In the baseline assessment, the "crop-specific" allocation approach was applied to allocate LUC to different crops within each producing country. In Fig. 8, each point represents a different plant-based spread or plant-based cream scenario. Dots are displayed from highest to lowest LUC impacts calculated with the default "crop-specific" allocation approach. The crosses correspond to impacts calculated with the "shared responsibility" allocation approach. It shows that the default "crop-specific" approach, compared with the "shared responsibility" approach, generally allocates more LUC to the crops used in the plant-based spreads and plant-based creams (thus higher climate change impacts), with only a few exceptions. For all plant-based spreads and plant-based creams, the alternate allocation approach resulted in a $36 \%$ decrease to a $4 \%$ increase in total climate change impacts, with an average decrease of $12 \%$, 

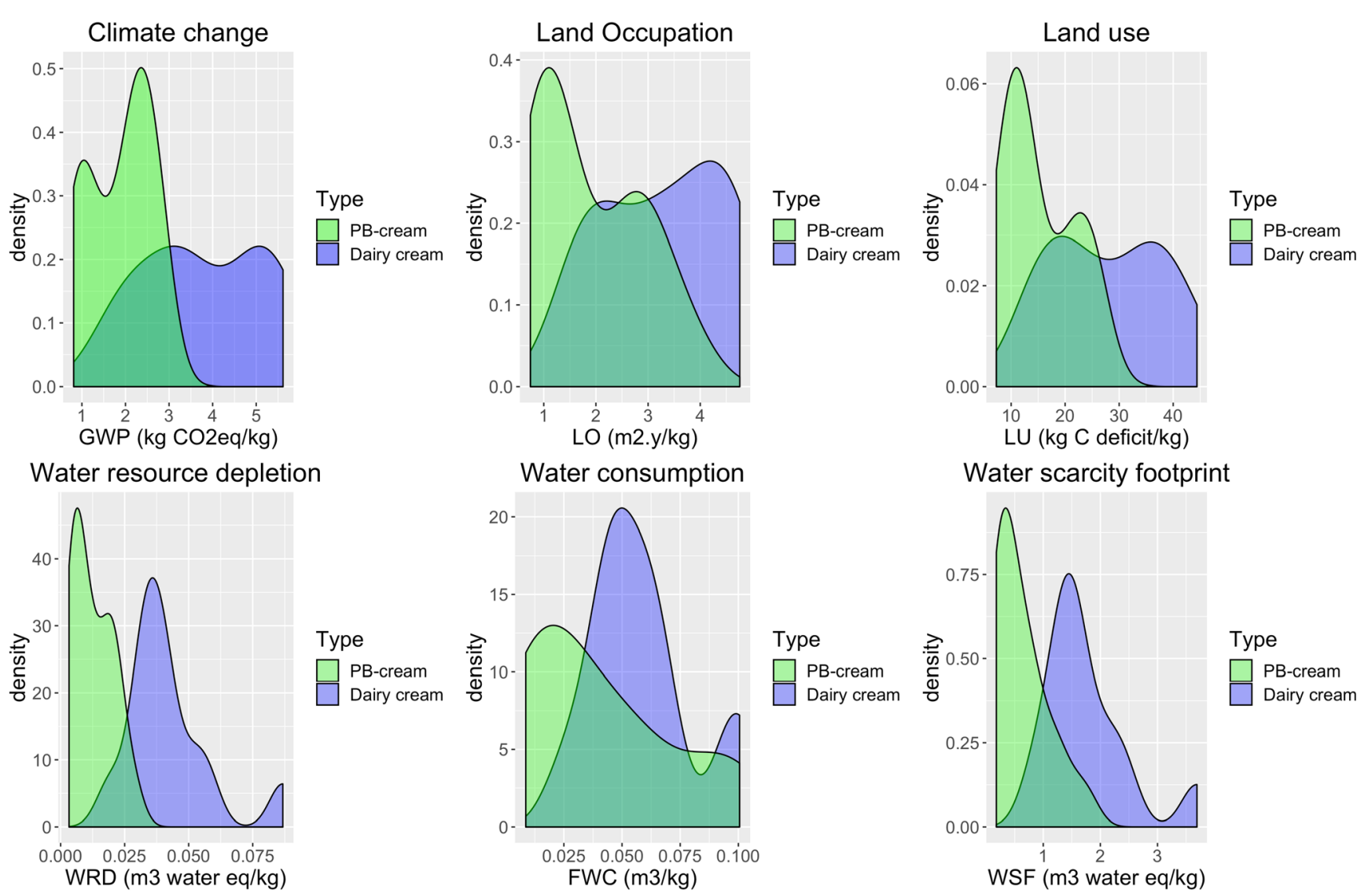

Fig. 6 Comparison of environmental impacts between plant-based creams and dairy creams in all 21 markets

because crop-specific burden allocation approach attributes more GHG emissions to vegetable oilseeds ingredients included in this assessment. Overall, it shows the choice of cropspecific allocation approach as default is a more conservative allocation approach. For both allocation approaches, with respect to the comparative impacts of plant-based products and dairy butter and cream, climate change impacts remain stable.

\subsubsection{The worst-case sourcing scenario comparison for vegetable oils supply chain}

Since vegetable oils are sourced worldwide and are traded as commodities, the countries of origin are generally known but the exact share from each country is unknown. Further, these proportions may vary from year to year. The LCA model assessed this data gap by considering import and production volume based on average historical FAOSTAT data, for each country where a factory producing the studied products is located. This sensitivity analysis aimed at generating a virtual "worst-case" scenario by considering sourcing countries with the highest climate change impacts for the main vegetable oils used in the plant-based spreads and plant-based creams. The following assumptions were made: $100 \%$ of palm oil and palm kernel oil sourced from Indonesia, $100 \%$ of sunflower oil sourced from Ukraine, $100 \%$ of rapeseed oil sourced from Australia, $100 \%$ of soybean oil sourced from Brazil and 100\% of linseed oil sourced from Kazakhstan. A virtual "best case" scenario was considered for butter and dairy cream, where no LUC took place in the feed supply chain, giving a fair representation of non-fodder feed ingredients being sourced locally. The results from this sensitivity analysis demonstrates that even if plant-based spreads used vegetable oils with the highest climate change impacts (generally due to LUC in sourcing countries), total climate change impacts remained lower than dairy butter for 204 of the 212 plant-based products analysed in 19 respective consumer markets. For 8 of the 212 products in Finland and Sweden, this "worst-case supply chain" scenario lead to climate change impacts that were $1 \%$ to $39 \%$ higher compared with "LUC free" butter. We found that the dairy systems in these two countries have much lower climate impacts compared with other countries and also the LUC induced climate impacts for these plant-based spreads were found to be quite high, highlighting the importance of quantifying regional supply chain information of ingredient sourcing as well as associated spatially differentiated LUC impact.

\subsection{Further sensitivity analysis}

In this study, we performed further sensitivity analyses regarding functional unit choice, vegetable oils extraction allocation 
Fig. 7 Contribution of LUC to climate change impacts $(\mathrm{kg} \mathrm{CO} 2$ $\mathrm{eq} / \mathrm{kg}$ ) for selected ingredients and final products

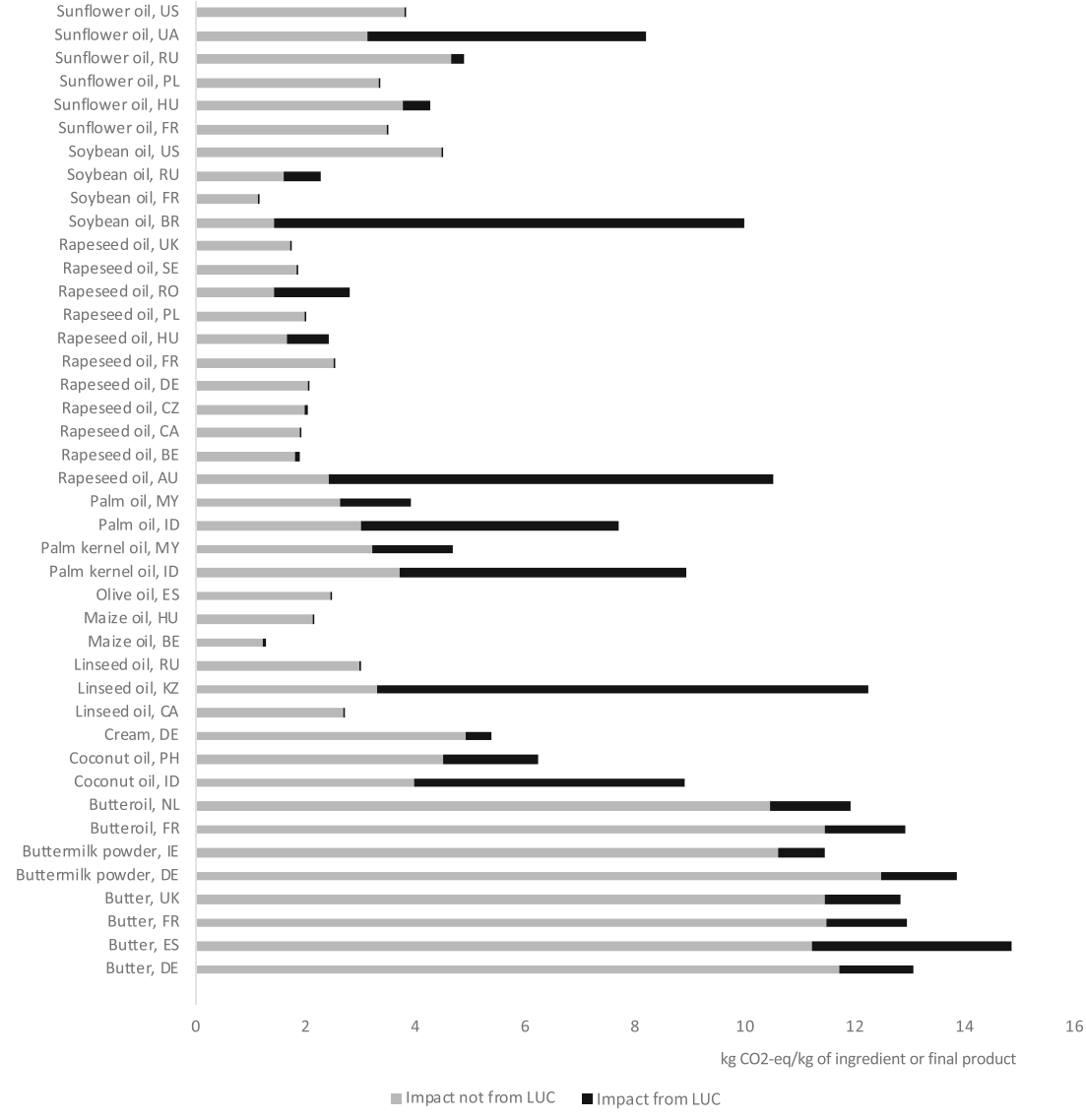

approach, packaging types and electricity production mix. Detailed discussions and results for each sensitivity analysis are available in the ESM (ESM 1.docx. Section 7). A summary of key insights obtained are discussed below.

\section{- Function unit choice}

The general trend for the LCA results was similar when considering a FU based on mass or volume. We also investigated the influence of considering a FU based on the total fat content, rather than on the total fresh mass, because most plant-based spreads generally have a lower fat content than butter, and a higher fact content often leads to higher climate, water and land impacts, vice versa (see more details in the ESM, Fig. S1). Such consideration seems of low relevance when products are used for spreading based on volume, but could be pertinent when used in baking if, for instance, the percentage of fat used in a cake recipe influences the quality of the cake in terms of taste/performance. The total fat in a plantbased spread ranges from $300-800 \mathrm{~g} / \mathrm{kg}$, allowing consumers to choose the spread that best suits the required function e.g. spreading or baking. Plant-based creams often have a lower fat content than dairy cream, some even with a particularly low-fat content of $<100 \mathrm{~g} / \mathrm{kg}$. Butter typically has a total fat content of $800 \mathrm{~g} / \mathrm{kg}$ and dairy creams in the present study had a total fat content ranging from 150 to $400 \mathrm{~g} / \mathrm{kg}$. For plantbased spreads, when changing the FU, the original conclusion still holds for climate change; similar patterns hold for water and land impact categories. As with the mass-based FU, there are significant overlaps between plant-based creams and dairy creams, and also between dairy spreads and butter. With a fatbased FU, the overlaps are more pronounced.

- Allocation method for vegetable oil extraction

A sensitivity analysis was performed considering mass allocation in the vegetable oil extraction processes rather than the default economic allocation. Mass allocation generally attributes a lower share of the upstream burden to crude oil compared with economic allocation. The only exception is maize oil with a mass allocation factor of $19.6 \%$ and an economic allocation factor of $18.0 \%$ for the crude oil. The analysis showed that the total impacts of plant-based spreads and plant-based creams when mass allocation was applied was systematically lower than calculated for the baseline scenario, showing that the application of economic allocation for oil extraction and processing is rather conservative and is not likely to change the conclusions of the study. 
Fig. 8 Climate change impacts (kg CO2-eq/kg) depending on LUC allocation approach (Each point represents a different plantbased spread or plant-based cream scenario. Dots are displayed from highest to lowest LUC impacts calculated with the default crop-specific allocation approach. The crosses correspond to impacts calculated with the shared responsibility allocation approach)

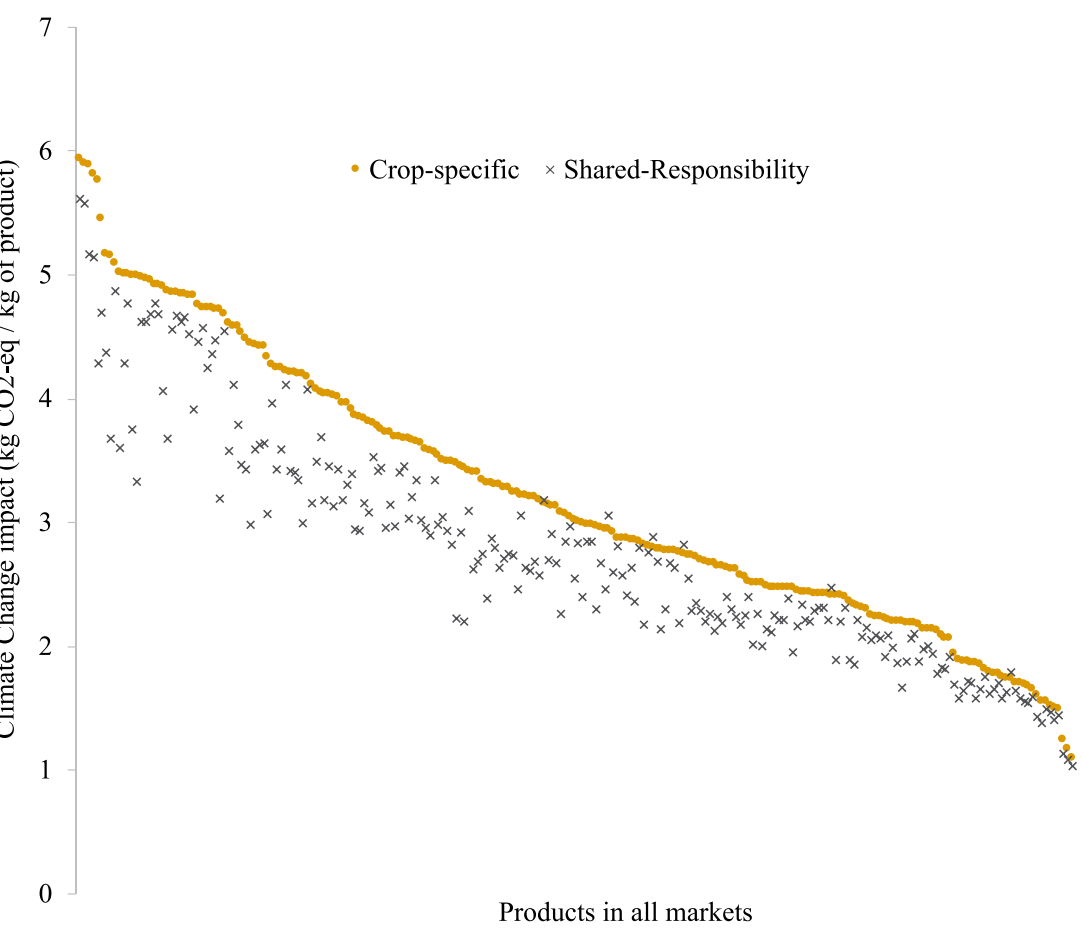

\subsection{Uncertainty analysis of climate change results}

The robustness of climate change results is evaluated through an uncertainty assessment as described in Section 2.6. As shown in Fig. 9, the uncertainty analysis shows that the higher bound of all 212 spreads, ranging from 0.98 to 6.93 (mean $3.3) \mathrm{kg} \mathrm{CO} 2-\mathrm{eq}$, still have lower climate change impacts compared with the lower bound of all 21 butter products, ranging from 8.08 to 16.93 (mean 12.1) kg CO2-eq with 95th confidence interval. However, the overlap of climate change results between plant-based spreads/creams and dairy spreads/creams increased.

\section{Conclusions and outlook}

The regionalised LCA conducted in this study is the largest scale regionalised agricultural LCA analysis comparing dairy butter and plant-based spreads published to date. It shows that plant-based spreads have lower climate, water and land impacts than butter, despite variability in product recipes and geographies and influence of LUC emissions. For climate change, the analysis shows all plant-based spreads perform better than butter regardless of the choice of functional unit (mass-based or fat-based), inclusion of LUC or allocation approach of oilseeds. It also shows that LUC of oilseed ingredients could dominate climate impacts for plant-based spreads; further, the hypothetical worst-case sourcing scenario (i.e. with the worst combination of oilseed type and sourcing country) performs worse than butter for climate impact, due to LUC associated with growing oilseed ingredients. Thus, inclusion of spatial LUC emissions is important for robust assessment and hotspot identification when taking steps towards mitigating the climate impact of food products. With respect to land occupation and water scarcity footprint, most plant-based spreads had lower impacts compared with butter in their respective consumer markets, with only a few exceptions ( 8 of 212 products) which contained oilseed ingredients with high embodied impacts, caused by either very low yield or very high water demand from growing in high water-stressed regions.

Towards transparency of sustainable supply chains and developing potential mitigation strategies, producers can only understand the impacts of their products and look for opportunities to reduce these impacts if they fully and accurately assess their product supply chains. The regionalised LCA results highlight significant interindividual variabilities on the product level for plant-based spreads, driven by differences in product recipe designs and spatial variabilities of sourcing ingredients.

The framework introduced and demonstrated in this study offers opportunities for hotspot identification as well as insights for improving the sustainability of a large portfolio of products. For example, towards more sustainable plant-based spreads, the key solution would be to reduce embodied environmental impacts from oilseed ingredients through better understanding and improvements in supply chain sourcing, farm level agricultural practice and product recipe design. The key challenges of performing large-scale regionalised LCA lies in the collection and organisation of all relevant data and models, performing gap assessment and prioritisation, developing missing data or improving data quality and also linking 


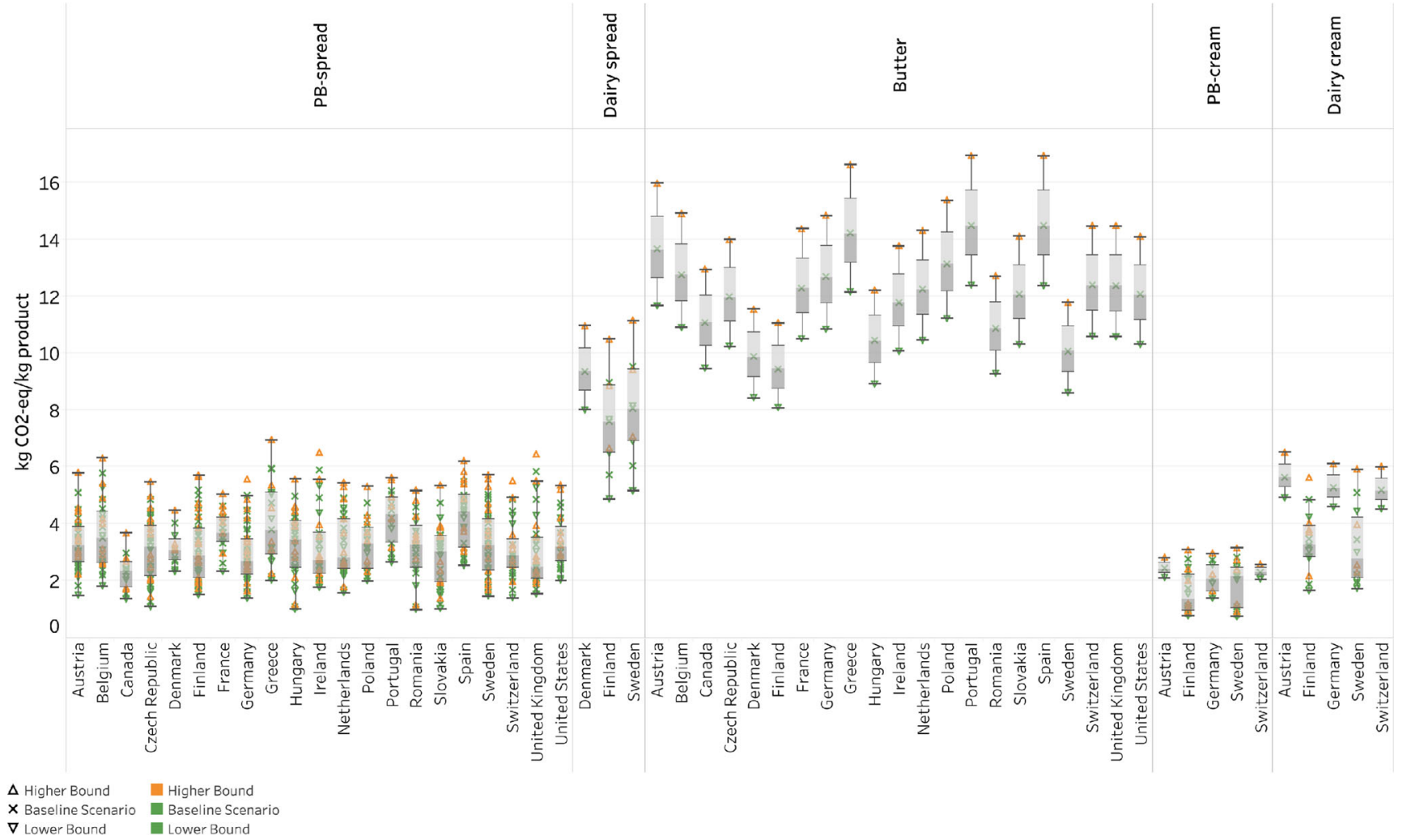

Fig. 9 Uncertainty analysis of climate change impacts of plant-based and dairy products

inventory data with impact assessment, to draw robust conclusions and meet requirements for data quality.

The application of the methodology framework in this study demonstrated the feasibility of conducting large-scale regionalised LCA for agri-food products. This principle is also relevant for other product type evaluations and this study offers step-wise guidance. We believe it will contribute to the operationalisation of regionalised LCA in practice towards identifying inter-product variabilities as well as highlighting hotspots for improving transparency and sustainability of product supply chains.

When moving towards developing more tangible mitigation strategies on a finer spatial scale, such as field or farm level intervention, it is important to verify the findings obtained from a high-level spatial scale and interpret the variabilities and hotspots identified by the country-scale regionalised LCA. This requires further improving (1) transparency and accuracy of supply chain sourcing information of key ingredients, (2) gathering, modelling and understanding agricultural information at a finer scale for parameters such as soil health and fertility characteristics, climate factors, crop yield, fertilising and irrigation situations etc, through techniques, such as field sensors, surveys or remote sensing data, as well as potential predictive analysis of future scenarios coupling with geographical information system (GIS) features; (3) a more robust modelling and understanding of spatialsensitive environmental mechanisms and the links between activity data and impact assessment.

Authors' contributions Xun Liao conceived the methodology framework in this paper and overall modelling architecture, building the supply chain modelling and system modelling tool, performing analysis, data visualisation, interpretation and main writing of the manuscript. Monique Gerichhausen contributed to the writing of the manuscript. Xavier Bengoa contributed to the discussion of defining the overall modelling architecture, the spatial agricultural LCI dataset development, gap assessment and analysis, and provided inputs for the writing. Giles Rigarlsford contributed to giving valuable inputs and improving the writing of the manuscripts. Ralph Beverloo and Yvonne Bruggeman contributed to primary data collection. Vincent Rossi contributed to the dairy system modelling and updated LUC modelling.

Open Access This article is licensed under a Creative Commons Attribution 4.0 International License, which permits use, sharing, adaptation, distribution and reproduction in any medium or format, as long as you give appropriate credit to the original author(s) and the source, provide a link to the Creative Commons licence, and indicate if changes were made. The images or other third party material in this article are included in the article's Creative Commons licence, unless indicated otherwise in a credit line to the material. If material is not included in the article's Creative Commons licence and your intended use is not permitted by statutory regulation or exceeds the permitted use, you will need to obtain permission directly from the copyright holder. To view a copy of this licence, visit http://creativecommons.org/licenses/by/4.0/. 


\section{References}

Blonk Agri-footprint BV (2015) Agri-footprint - Part 2 - Description of data. Gouda, the Netherland

Blonk Consultants (2013) Direct Land Use Change Assessment Tool Version 2013.1

Boulay A-M et al (2018) The WULCA consensus characterization model for water scarcity footprints: assessing impacts of water consumption based on available water remaining (AWARE). Int J Life Cycle Assess 23:368-378

BSI (2012) PAS 2050-1:2012 Assessment of life cycle greenhouse gas emissions from horticultural products. British Standard Institute, London

Conway D, van Garderen EA, Deryng D et al (2015) Climate and southern Africa's water-energy-food nexus. Nat Clim Chang 5:837-846

DFC (2012) Environmental and socioeconomic life cycle assessment of Canadian Milk. Dairy Farmers of Canada, Montreal

Djekic I, Miocinovic J, Tomasevic I, Smigic N, et all (2014) Environmental life-cycle assessment of various dairy products. J Clean Prod 68:64-72

EDA (2016) Product environmental footprint category rules for dairy products. Draft report (28 July 2016). The European Dairy Association, Brussels

Ekvall T, Tillman A-M (1997) Open-loop recycling: Criteria for allocation procedures. Int J Life Cycle Assess 2:155

ESDAC (2010) European Soil Data Centre: http://esdac.jrc.ec.europa.eu/ resource-type/datasets. Accessed online in 2012

European Commission (2017) PEFCR guidance document, - guidance for the development of Product Environmental Footprint Category Rules (PEFCRs), version 6.3, December 152017

FAO (2010a) Greenhouse gas emissions from the dairy sector - a life cycle assessment. Animal Production and Health Division, Food and Agriculture Organization of the United Nations. Online, Rome

FAO (2010b) Global Forest Resource Assessment 2010. Food and Agriculture Organization of the United Nations. Accessed online in May 2013: http://www.fao.org/forestry/fra/fra2010/en

FAO, IDF, IFCN (2014) World mapping of animal feeding systems in the dairy sector. Food and Agriculture Organisation of the United Nations, the International Dairy Federation, the IFCN Dairy Research Network, Rome

FAOSTAT (2006-2011) Vegetable oil production and import volumes. //faostat.fao.org/. Accessed Nov 2016

FAOSTAT (2012) Data cover up to the year 2011 and are sourced from http://faostat.fao.org/. Accessed May 2013

Flysjö A (2012) Greenhouse gas emissions in milk and dairy product chains: Improving the carbon footprint of dairy products. Aarhus University, Department of Agroecology

GHG Protocol (2011) Quantitative inventory uncertainty. www. ghgprotocol.org/sites/default/files/ghg-uncertainty.pdf. Accessed 5th September 2016

Hellweg S, Milà i Canals L (2014) Emerging approaches, challenges and opportunities in life cycle assessment. Science 344:1109-1113

IDF (2015) A common carbon footprint approach for Dairy. The IDF guide to standard life cycle assessment methodology for the dairy sector. International Dairy Federation, Brussels

IPCC (2006) IPCC guidelines for national greenhouse gas inventories. Volume 4: Agriculture, forestry and other land use. IGES, Kanagawa, Japan

IPCC (2013) Adoption and acceptance of the "2013 supplement to the 2006 guidelines: Wetlands" (Vol. 2). Geneva, Switzerland

ISO (2006a) Environmental management - life cycle assessment - principles and framework, ISO 14040:2006(E). International Organization for Standardization, Geneva
ISO (2006b) Environmental management - life cycle assessment - requirements and guidelines, ISO 14044:2006(E). International Organization for Standardization, Geneva

JRC-IES (2011) International Reference Life Cycle Data System (ILCD) Handbook- Recommendations for Life Cycle Impact Assessment in the European context. In: European Commission-Joint Research Centre - Institute for Environment and Sustainability, 1st edn. Publications Office of the European Union, Luxemburg

Joosten H (2009) The Global Peatland CO2 Picture Peatland status and drainage related emissions in all countries of the world. Wetlands International, Ede

Kraucunas I, Clarke L, Dirks J et al (2015) Investigating the nexus of climate, energy, water, and land at decision-relevant scales: the Platform for Regional Integrated Modeling and Analysis (PRIMA). Clim Chang 129:573-588

LEAP (2015) Environmental performance of animal feeds supply chains: guidelines for assessment. In: Livestock Environmental Assessment and Performance Partnership. The Food and Agriculture Organization of the United Nations (FAO), Rome

Milà i Canals L, Rigarlsford G, Sim S (2012) Land use impact assessment of margarine. Int J Life Cycle Assess 18(6):1265-1277

Milà i Canals L, Rigarlsford G, Sim S (2013) Land use impact assessment of margarine. The International Journal of Life Cycle Assessment 18(6):1265-1277

Nemecek T, Gaillard G, Freiermuth R, Antón A, Wilfart-Monziols A, Hermansen J (2011) ecoinvent V3.0 - good practice for life cycle inventories in agriculture (plant and animal production). Version: 1.4 - June 2011. Agroscope Reckenholz-Taenikon Research Station ART, Swiss Centre for Life Cycle Inventories, Zurich and Dübendorf, Switzerland

Nemecek T, Schnetzer J, Reinhard J (2014) Updated and harmonised greenhouse gas emissions for crop inventories. Int J Life Cycle Assess 21(9):1361-1378

Nemecek T, Bengoa X, Lansche J, et al (2015) Methodological guidelines for the life cycle inventory of agricultural products. Version 3.0., July 2015. World Food LCA Database (WFLDB)

Nikolaou CK, Hankey CR, Lean ME (2016) Effects of calorie labelling on macro- and micro-nutrients in main-meal choices made by young adults. Eur J Clin Nutr 70:386-392

Nilsson K, Flysjö A, Davis J, et al (2010) Comparative life cycle assessment of margarine and butter consumed in the UK, Germany and France. Int J Life Cycle Assess 15:916-926

Pendrill F, Persson UM, Godar J et al (2019) Agricultural and forestry trade drives large share of tropical deforestation emissions. Glob Environ Chang 56:1-10

Poore J, Nemecek T (2018) Reducing food's environmental impacts through producers and consumers. Science 360(6392):987-992

Quantis (2016) ALCIG - Agricultural Life Cycle Inventory Generator. https://alcig.quantis-software.com. Accessed 9 July 2019

Ranganathan J, Vennard D, Waite R, et al (2016) Shifting diets for a sustainable food future. World Resources Institute

Ringler C, Bhaduri A, Lawford R (2013) The nexus across water, energy, land and food (WELF): potential for improved resource use efficiency? Curr Opin Environ Sustain 5:617-624

Sandström V, Valin H, Krisztin T et al (2018) The role of trade in the greenhouse gas footprints of EU diets. Glob Food Secur 19:48-55

Schau EM, Palomino J-A, Michalopoulos G, et al (2016) Product environmental footprint category rules for olive oil - 3rd Draft. Draft version 0.5. Web URL: http://ec.europa.eu/environment/eussd/ smgp/pdf/pilots/draft_pefcr_olive_oil_pilot_for_3rd_consultation. pdf. Accessed June 10th, 2017 
Thoma G, Popp J, Nutter D et al (2013) Greenhouse gas emissions from milk production and consumption in the United States: A cradle-tograve life cycle assessment circa 2008. Int Dairy J 31:S3-S14

UN Food and Agriculture Organization (2010) Greenhouse gas emissions from the dairy sector. A Life Cycle Assessment

UNEP (2016) Global guidance for life cycle impact assessment indicators. Vol 1. ISBN: 978-92-807-3630-4

Vermeulen SJ, Campbell BM, Ingram JSI (2012) Climate change and food systems. Annu Rev Environ Resour 37:195-222

Weidema BP, Bauer C, Hischier R, Mutel C, Nemecek T, Reinhard J, Vadenbo CO, Wernet G (2013) Overview and methodology. Data quality guideline for the ecoinvent database version 3 . Ecoinvent Report 1(v3). The ecoinvent Centre, St. Gallen
Wernet G, Bauer C, Steubing B, Reinhard J, Moreno-Ruiz E, Weidema B (2016) The ecoinvent database version 3 (part I): overview and methodology. Int J Life Cycle Assess 21(9):1218-1230

Wickham H (2016). ggplot2: Elegant Graphics for Data Analysis. Springer-Verlag New York. ISBN 978-3-319-24277-4

Willett W, Rockström J, Loken B et al (2019) Food in the Anthropocene: the EAT-Lancet Commission on healthy diets from sustainable food systems. Lancet. https://doi.org/10.1016/S0140-6736(18)31788-4

Publisher's note Springer Nature remains neutral with regard to jurisdictional claims in published maps and institutional affiliations.

\section{Affiliations}

\section{Xun Liao $^{1,2}$ (D) $\cdot$ Monique J. W. Gerichhausen $^{3} \cdot$ Xavier Bengoa $^{1} \cdot$ Giles Rigarlsford $^{4} \cdot$ Ralph H. Beverloo $^{5}$. Yvonne Bruggeman ${ }^{3} \cdot$ Vincent Rossi $^{1}$}

1 Quantis, EPFL Innovation Park Bât. D, 1015 Lausanne, Switzerland

2 Industrial Process and Energy Systems Engineering, Ecole Polytechnique Fédérale de Lausanne, EPFL Valais Wallis, Rue de l' Industrie 17, 1951 Sion, Switzerland
3 Upfield Research and Development, Nassaukade 3, 3071 Rotterdam, JL, Netherlands

4 Unilever Safety and Environmental Assurance Centre, Unilever R\&D, Colworth Science Park, Sharnbrook MK44 1LQ, UK

5 Rotterdam, Netherlands 